\title{
A demographic profile of cervical injury: an Indonesian single tertiary hospital study with 6 months to 1-year follow-up
}

\author{
Lukas Widhiyanto ${ }^{*}$, Aliefio Japamadisaw and Kukuh Dwiputra Hernugrahanto
}

\begin{abstract}
Background: Spinal cord injury (SCl) can cause considerable morbidity and mortality. Until now there is no spinal cord injury profile in Indonesia. Therefore, this study aims to provide an overview of the spinal cord injury profile as well as to analyze the functional outcome at the sixth month and the first year.

Results: Most spinal cord injury cases were traumatic SCI (67.5\%). Meanwhile, non-traumatic SCI was 32.5\%. The mean age of patients who had traumatic SCI was $41.9 \pm 17.4$ years while non-traumatic SCI patients was $48.4 \pm 13.7$ with a significant difference $(p<0.05)$. Most cases occurred in men rather than women with significant differences based on the type of injury $(p<0.05)$. Traffic accidents were the most common cause of cervical injuries $(47.1 \%)$. Surgery was the most common treatment modality in cervical injury cases (60.4\%) with the posterior approach being the preferred approach in most operative measures (72.4\%). Respiratory failure was the leading cause of death (48.9\%). The mean LOS of patients with traumatic SCI was $28.8 \pm 14.3$ days while the mean LOS of non-traumatic SCI patients was $44.7 \pm 28.7$ with a significant difference $(p<0.05)$. There was significance difference between the initial outcome and after the sixth month to first year follow-up $(p<0.05)$.
\end{abstract}

Conclusions: This study demonstrated the epidemiology and characteristics of spinal cord injury which mostly had a good neurological outcome.

Keywords: Cervical Injury, Frankel, Spinal Cord Injury

\section{Background}

Spinal cord injury (SCI) can cause considerable morbidity and mortality. Spinal cord injury (SCI) can be nontraumatic or traumatic. In non-traumatic cases, generally in the form of degenerative diseases, infections and neoplasms [1]. The most common causes of traumatic SCI are traffic accidents, falls, diving and vigorous sports. There is a tendency for spinal cord injuries to occur more in men, this result may be due to men consuming more alcohol, have a habit of driving at high speeds and participating in sports with a high risk of injury [2, 3].

*Correspondence: lukas-w@fk.unair.ac.id

Department of Orthopedic and Traumatology, Dr. Soetomo General

Hospital/Airlangga University, Surabaya, Indonesia
There are no data that clearly explains the profile of spinal cord injuries, whether caused by trauma or nontrauma, starting from demographic data to outcomes obtained by patients in Indonesia, especially at Dr. Soetomo Hospital, Surabaya. Spinal cord injury profile data is very important, because it can be used as educational information and evaluation of spinal cord injury management. Therefore, this study aims to provide an overview of the spinal cord injury profile in patients at Dr. Soetomo General Hospital in Surabaya for the period 2017-2019.

\section{Methods}

This research was conducted at Dr. Soetomo General Hospital in Surabaya, Indonesia. This is a retrospective study which was conducted with a descriptive and 
analytical design. The analysis focused on patient-related data including age, sex, mechanism of injury, type \& level of injury, type of therapy, length of stay, and patient outcome (live, died and neurological status).

This study used secondary data obtained from the patient's medical records in the Medical Records Section and the Outpatient Installation of Dr. Soetomo General Hospital. Ethical approval for this study was obtained from Health Research Ethics Committee-Dr. Soetomo General Hospital (1802/KEPK/I/2020). This study using total sampling. The collected data were then analyzed descriptively. The age, sex, and the outcome data were also analyzed analytically using SPSS.

\section{Results}

Based on the data obtained, the number of samples that should be used is 144 based on the index data of the Spine Division of the Orthopedics \& Traumatology Department, with 142 samples available in the data collection time period. Among the available samples, 126 data (88.7\%) were valid based on predetermined inclusion and exclusion criteria. Based on the data found, traumatic SCI was the most common type of cervical injury, with a total of 85 cases $(67.5 \%)$, while non-traumatic SCI had a total of 41 cases $(32.5 \%)$.

According to the data shown in Table 1, spinal cord injury cases occurred most frequently in the 35-54 years age group with a total of 55 cases (43.7\%). The mean age of patients with traumatic SCI was $41.9 \pm 17.4$ years, while the mean age of non-traumatic SCI patients was $48.4 \pm 13.7$. According to $t$ test, it had a significant difference $(p=0.025)$.

Spinal cord injury cases were more common in male patients with 100 cases $(79.4 \%)$ mostly traumatic SCI, while for female gender, 26 cases $(20.6 \%)$ were found with details of each of the 13 patients in both types of

Table 1 Distribution of data by age and sex

\begin{tabular}{ccccr}
\hline Variable & \multicolumn{2}{l}{ Total $(\boldsymbol{n})$} & Total & (\%) \\
\cline { 2 - 3 } & Traumatic SCl & $\begin{array}{l}\text { Non } \\
\text { traumatic SCl }\end{array}$ & \\
\hline Age & & & 4 & \\
$0-14$ & 3 & 1 & 31 & 24.6 \\
$15-34$ & 27 & 4 & 55 & 43.7 \\
$35-54$ & 33 & 22 & 34 & 26.9 \\
$55-74$ & 21 & 13 & 2 & 1.6 \\
$\geq 75$ & 1 & 1 & 100 & 79.4 \\
Sex & & & 26 & 20.6 \\
Men & 72 & 28 & & \\
Women & 13 & 13 & & \\
\hline
\end{tabular}

cervical injury. From this data, a Chi Square test was performed and the $\mathrm{p}$ value was obtained $=0.033(p<0.05)$, which means that there were significant differences in the number of male and female groups based on the type of injury.

In Table 2, it can be seen that the most common injury mechanisms causing traumatic SCI were traffic accidents in 40 cases (47.1\%), followed by falls from a height of 32 cases (37.6\%), and heavy objects hit by 7 cases (8.2\%) and simple fall as many as 6 cases $(7.1 \%)$. traumatic SCI were more common in the lower cervical as many as 71 cases $(83.5 \%)$ compared to upper cervical as many as 14 cases $(16.5 \%)$ with a ratio of $5: 1$. The cause of non-traumatic SCI was mostly caused by degenerative diseases in 25 cases $(62 \%)$, followed by neoplasms in 9 cases $(22 \%)$, infection in 6 cases (14.6\%) and congenital disease in 1 case (2.4\%).

A total of 83 patients (65.9\%) were alive after undergoing treatment at Dr. Soetomo General Hospital, with details of 22 patients undergoing conservative therapy and 61 patients undergoing operative therapy. Meanwhile, there were 43 patients (34.1\%) who died after undergoing treatment at the Dr. Soetomo General Hospital with details as followed; 3 patients had conservative therapy, 15 patients underwent operative therapy, and 25 patients had not undergone surgery.

Based on Table 3, there were 25 patients who had not had surgery (19.8\%), because the patient died before surgery, 25 patients $(19.8 \%)$ received conservative therapy with details of 22 traumatic SCI patients and 3 patients with non-traumatic SCI. Meanwhile, of the 76 patients who received operative therapy, 21 cases $(27.6 \%)$ had an anterior approach in surgery with details as followed; 7 patients with traumatic SCI and 14 non-traumatic SCI patients. The remaining 55 cases $(72.4 \%)$ had a posterior

Table 2 Distribution of data based on mechanism of injury

\begin{tabular}{lcc}
\hline Variable & Total $(\boldsymbol{n})$ & (\%) \\
\hline Mechanism of injury traumatic SCI & & \\
$\quad$ Trivial Injury & 6 & 7.1 \\
Fall from Height & 32 & 37.6 \\
Traffic Accident & 40 & 47.1 \\
Heavy objects hit & 7 & 8.2 \\
Level of injury traumatic SCl & & \\
Lower Cervical & 71 & 83.5 \\
Upper Cervical & 14 & 16.5 \\
Causes of non traumatic SCl & & \\
$\quad$ Degenerative & 25 & 62 \\
Infection & 6 & 14.6 \\
Neoplasms & 9 & 22 \\
Congenital disease & 1 & 2.4 \\
\hline
\end{tabular}


Table 3 Distribution of data based on treatment modalities, surgical approach and causes of death

\begin{tabular}{|c|c|c|c|c|}
\hline \multirow[t]{2}{*}{ Variable } & \multicolumn{2}{|l|}{ Total $(n)$} & \multirow[t]{2}{*}{ Total } & \multirow[t]{2}{*}{$\%$} \\
\hline & Traumatic SCI & $\begin{array}{l}\text { Non } \\
\text { traumatic } \\
\mathrm{SCl}\end{array}$ & & \\
\hline \multicolumn{5}{|l|}{ Treatment modalities } \\
\hline Surgery not done & 21 & 4 & 25 & 19.8 \\
\hline Conservative & 22 & 3 & 25 & 19.8 \\
\hline Operative & 42 & 34 & 76 & 60.4 \\
\hline \multicolumn{5}{|l|}{ Surgical approach } \\
\hline Anterior & 7 & 14 & 21 & 27.6 \\
\hline Posterior & 35 & 20 & 55 & 72.4 \\
\hline \multicolumn{5}{|l|}{ Causes of death } \\
\hline Respiratory failure & 18 & 3 & 21 & 48.9 \\
\hline Cardiovascular & 0 & 1 & 1 & 2.3 \\
\hline Sepsis & 19 & 1 & 20 & 46.5 \\
\hline Neurogenic shock & 1 & 0 & 1 & 2.3 \\
\hline
\end{tabular}

approach to surgery with details as followed; 35 traumatic SCI patients and 20 non-traumatic SCI patients. From the total 43 patients who died, the leading cause of death for cervical injuries was respiratory failure (21 cases, $48.9 \%$ ).

Table 4 shows the difference between the degree of injury at the initial measurement, which is at the time of completion of hospitalization with the degree of injury at follow-up 6 months to 1 year after discharged. From the statistical analysis of the Chi square test, it was found that there was a significant difference between the initial injury degree group and the 6 months to 1-year followup injury degree group after discharged with a value of $p=0.000(p<0.05)$. This could be seen from the number of patients. From 6 patients in the Frankel A group, who were followed up after discharged, 2 patients improved to Frankel D, 2 patients improved to Frankel C and 2 patients improved to Frankel B. From 9 patients in Frankel B group, 2 patients improved to Frankel E, 2 patients improved to Frankel D, 3 patients improved to Frankel C, and 2 patients were still in Frankel B. From 16 patients in Frankel $\mathrm{C}$ group, 5 patients improved to Frankel E, 5 patients improved to Frankel D, and 6 patients were still in Frankel C. From 22 patients in Frankel D group,13 patients improved to Frankel E, 8 were still in Frankel D. However, there was 1 patient who deteriorated to Frankel $\mathrm{C}$ after followed up.

In the variable length of stay (LOS), using Mann Whitney test, Cervical patients who survived for $35.7 \pm 23.0$ days and who died for $19.3 \pm 16.7$ days with a significant difference $(p=0.000)$.

Table 5 showed the mean Length of Stay (LOS) of cervical injury patients who survived for $35.7 \pm 23.0$ days

Table 5 Differences between mean length of stay (LOS) in cervical injury patients

\begin{tabular}{lllcl}
\hline LOS & $\begin{array}{l}\text { Mean LOS } \pm \text { SD } \\
\text { (day) }\end{array}$ & Min. (day) & Max (day) & \\
\hline Survived & $35.7 \pm 23.0$ & 6 & 123 & $p=0.000$ \\
Dead & $19.3 \pm 16.7$ & 1 & 65 & \\
Traumatic SCl & $28.8 \pm 14.3$ & 7 & 66 & $p=0.004$ \\
Non traumatic & $44.7 \pm 28.7$ & 6 & 123 & \\
SCl & & & & \\
\hline
\end{tabular}

Table 4 Differences between degrees of injury according to Frankel scale

\begin{tabular}{|c|c|c|c|c|c|c|}
\hline & \multicolumn{4}{|c|}{ Frankel 6 months- 1 year after discharge } & \multirow[t]{2}{*}{ Total } & \\
\hline & B & $\mathrm{C}$ & D & $\mathrm{E}$ & & \\
\hline \multicolumn{7}{|c|}{ Initial Frankel } \\
\hline \multirow[t]{2}{*}{ A } & 2 & 2 & 2 & 0 & 6 & $p=0.000$ \\
\hline & $2.4 \%$ & $2.4 \%$ & $2.4 \%$ & $0 \%$ & $7.2 \%$ & \\
\hline \multirow[t]{2}{*}{ B } & 2 & 3 & 2 & 2 & 9 & \\
\hline & $2.4 \%$ & $3.6 \%$ & $2.4 \%$ & $2.4 \%$ & $10.8 \%$ & \\
\hline \multirow[t]{2}{*}{ C } & 0 & 6 & 5 & 5 & 16 & \\
\hline & $0 \%$ & $7.2 \%$ & $6.0 \%$ & $6.0 \%$ & $19.3 \%$ & \\
\hline \multirow[t]{2}{*}{ D } & 0 & 1 & 8 & 13 & 22 & \\
\hline & $0 \%$ & $1.2 \%$ & $9.6 \%$ & $15.7 \%$ & $26.5 \%$ & \\
\hline \multirow[t]{2}{*}{ E } & 0 & 0 & 0 & 30 & 30 & \\
\hline & $0 \%$ & $0 \%$ & $0 \%$ & $36.1 \%$ & $36.1 \%$ & \\
\hline Total & 4 & 12 & 17 & 50 & 83 & \\
\hline
\end{tabular}


and who died for $19.3 \pm 16.7$ days with a significant difference $(p=0.000)$. Meanwhile, the mean LOS of patients with traumatic SCI was $28.8 \pm 14.3$ and the mean LOS of non-traumatic SCI patients was $44.7 \pm 28.7$ with a significant difference $(p=0.004)$.

\section{Discussions}

In this study, out of 126 total spinal cord injury patients that we could evaluate, it was found that the number of traumatic SCI cases was higher than that of non-traumatic SCI, namely, $67.5 \%$. This was in line with research conducted by Ones et al. [4] and Cosar et al. [5]. However, this result was different from research conducted by Ge et al. where the total number of non-traumatic SCI cases from 2003 to 2014 was greater than SCI caused by trauma in Rochester, United States [6].

According to the results obtained, the mean age of patients with traumatic SCI was younger than the mean age of non-traumatic SCI patients, namely, 41.9 years and 48.4 years. This result was in line with a study conducted by Cosar et al. [5]. Where the mean age of traumatic SCI patients was 37 years and was significantly younger than the average age of non-traumatic SCI patients. In a study conducted by van den Berg et al. in 2010, it showed a bimodal age distribution. The first peak was found in young adults between 15 and 29 years, mostly caused by traffic accidents. The second peak in older adults, aged more than 65 years, mostly caused by falls. Meanwhile, non-traumatic SCI was more common in elderly patients, because non-traumatic SCI was more often caused by age-related pathologies, such as tumors, degenerative diseases and vascular disorders [7].

In this study, men were more likely to experience cervical injuries than women with a ratio of 4: 1 . In both traumatic SCI and non-traumatic SCI, men were found to be more at risk of developing SCI. The data found by Igho et al. shows the same thing, where men had a higher risk and number of fracture events due to their high participation in physical activities, such as construction work, motorbike riding, and others [8].

Traffic accidents were the main cause of traumatic SCI incidence in this study. There were $47.1 \%$ of traumatic SCI caused by traffic accidents while falling from a height was the next most common cause of fracture at $37.6 \%$. These results were in line with a meta-analysis study conducted in the Middle East and North Africa, where in almost all countries the main cause of traumatic SCI events was traffic accidents [9]. According to Nantulya, the causes of the high number of traffic accidents in developing countries were the increasing number of motor vehicles, poor enforcement of traffic safety regulations, and poor road infrastructure [10].
In this study, it was found that traumatic SCI were more common in the lower cervical, namely, C3-C7 as many as 71 patients $(83.5 \%)$ while the upper cervical or $\mathrm{C} 1$ and $\mathrm{C} 2$ were 14 patients (16.5\%). These results were in line with research conducted by Wang, in China. From 2001 to 2010, 656 patients (70.9\%) had lower cervical fractures and 269 (29.1\%) upper cervical fractures [11]. The large number of fractures of the lower cervical spine was due to the biomechanical weakness of the cervical spine and a lot of movement in this region [12].

Non-traumatic SCI was caused by various conditions including degenerative diseases, neoplasms, infections, congenital diseases and vascular diseases. A research in the United States stated that the most common cause of non-traumatic SCI was degenerative disease [6]. The results of this study also showed a similar result in which $62 \%$ of non-traumatic SCI patients were caused by a degenerative disease. However, in other studies it was also mentioned that neoplasms were the most common cause [13].

The total number of cervical injury patients at $\mathrm{Dr}$ Soetomo General Hospital from 2017 to 2019 was 126 patients. Of the total 126 patients, 83 patients survived either after conservative or operative treatment, and 43 patients who died, either those who had definitive therapy or those who had not. The most common causes of death in this study were respiratory failure and sepsis. The results of this study were in line with research conducted by Savic et al. where $29.3 \%$ of 2170 patients from 1943 to 2010 in England died from respiratory failure [14], while according to Thietie et al. The most common cause of death in SCI patients in their study was sepsis [15]. Respiratory failure in SCI was caused by several mechanisms including weakness of the respiratory muscles, impaired cardiovascular function and autonomic nerves, pulmonary edema, prolonged bed rest, and impaired cough function [16]. While sepsis in cervical injury patients could be caused by several pathologies, including urinary tract infection due to repeated insertion of Foley catheters or impairment of bladder emptying, skin and soft tissue infection, such as pressure ulcer, surgical osteomyelitis, and pneumonia due to sputum retention [17].

In this study there were 76 patients (60.4\%) who underwent surgery, 25 patients (19.8\%) underwent conservative therapy, and 25 patients $(19.8 \%)$ died before surgery. Of the 76 patients who underwent surgery 55 patients $(72.4 \%)$ via the posterior approach and 21 patients $(27.6 \%)$ via the anterior approach. Either an anterior or a posterior approach can be chosen for stabilization of an unstable cervical injury based on the preference of the surgeon, indication and condition of the patient [18]. 
The mean length of stay (LOS) of traumatic SCI in this study was $28.8 \pm 14.3$ days. The mean length of stay (LOS) of non-traumatic SCI was $44.7 \pm 28.7$ days. There was a significant difference between the mean LOS of traumatic SCI and non-traumatic SCI patients $(p=0.004)$. This result was different from a study, conducted by Celani et al. where LOS in traumatic SCI was significantly longer than LOS in non-traumatic SCI. This might be because traumatic SCI was usually accompanied by other accompanying injuries, such as abdominal trauma, thoracic trauma, and multiple fractures [13]. Different results were shown in this study, because the majority of non-traumatic SCI patients had other comorbidities, such as neurological or metabolic disease.

In this study also found a significant improvement in neurological scores at 6 months to 1-year follow-up after discharged. The restoration of normal motor function depended on the re-organization of the remaining spinal circuit ring. This ability to reorganize, commonly referred to as plasticity, was thought to have a profound effect on recovery of function after injury, as well as learning and memory in the undamaged central nervous system. In undamaged nerves, there were changes in synaptic function and the pattern of connections between synapses within the nerve circuit ring. In addition, there was growth or sprouting of undamaged axons as compensation for injured axons [19].

\section{Conclusions}

This study was able to detect some interesting correlations that will be able to guide, especially primary care physicians in their initial diagnostic work up. However, this study also had limitations, the most obvious being the dependence upon the quality of the data recorded in the medical records.

\section{Abbreviations}

SCI: Spinal cord injury; LOS: Length of stay.

\section{Acknowledgements}

Not applicable.

\section{Authors' contributions}

LW conceived the ideas of the study, provide grammatical revisions to manuscript. AJ performed the data collection, analysis, interpretation and research funding. $\mathrm{KDH}$ provided revisions to scientific content of manuscript \& access to crucial research components. All authors read and approved the manuscript.

\section{Funding}

This research is self-funded.

\section{Availability of data and materials}

All data generated or analysed during this study are included in this published article.

\section{Declarations}

Ethics approval and consent to participate

Ethical approval for this study was obtained from Health Research Ethics Committee-Dr. Soetomo General Hospital (1802/KEPK//2020)

\section{Consent for publication}

Not applicable.

\section{Competing interests}

The authors declare that they have no competing interests.

Received: 7 June 2021 Accepted: 3 December 2021

Published online: 20 December 2021

\section{References}

1. Mineiro J. Apley \& solomon's system of orthopaedics and trauma. 10th ed. New York: CRC Press; 2018.

2. Kumar K, Subrahmanyam B, Phanidra S. Demographic pattern, clinical profile and outcome of traumatic spinal cord injuries at a tertiary care hospital. Rom Neurosurg. 2015;29(3):312-7.

3. Bickenbach J, Officer A, Shakespeare T. International perspectives on spinal cord injury. Malta: World Health Organization; 2013.

4. Ones K. Comparison of functional results in non-traumatic and traumatic spinal cord injury. Disabil Rehabil. 2007;29(15):1185-91.

5. Cosar S, Yemisci O, Oztop P. Demographic characteristics after traumatic and non-traumatic spinal cord injury: a retrospective comparison study. Spinal Cord. 2010;48(12):862-6.

6. Ge L, Arul K, Ikpeze T, Baldwin A, Nickels J, Mesfin A. Traumatic and nontraumatic spinal cord injuries. World Neurosurg. 2018;111:142-8.

7. van den Berg M, Castellote J, Mahillo-Fernandez I, de Pedro-Cuesta J. Incidence of spinal cord injury worldwide: a systematic review. Neuroepidemiology. 2010;34(3):184-92.

8. Igho O, Isaac $\mathrm{O}$, Eronimeh $\mathrm{O}$. Road traffic accidents and bone fractures in Ughelli, Nigeria. Sciences IOSR J Dent Med. 2015;14(4):21-5.

9. Elshahidi M, Monir N, Elzhery M. Epidemiological characteristics of traumatic spinal cord injury (TSCI) in the Middle-East and North-Africa (MENA) region: a systematic review and meta-analysis. Bull Emerg Trauma. 2018;6(2):75-89.

10. Nantulya V. The neglected epidemic: road traffic injuries in developing countries. BMJ. 2002;324(7346):1139-41.

11. Wang $H$, Xiang $Q, L i C$, Zhou Y. Epidemiology of traumatic cervical spinal fractures and risk factors for traumatic cervical spinal cord injury in China. J Spinal Disord Tech. 2013;26(8):306-13.

12. Feuchtbaum E, Buchowski J, Zebala L. Subaxial cervical spine trauma. Curr Rev Musculoskelet Med. 2016;9(4):496-504.

13. Celani M, Spizzichino L, Ricci S, Zampolini M, Franceschini M. Retrospective Study Group on SCI. Spinal cord injury in Italy: a multicenter retrospective study. Arch Phys Med Rehabil. 2001:82(5):589-96.

14. Savic G, DeVivo M, Frankel H, Jamous M, Soni B, Charlifue S. Causes of death after traumatic spinal cord injury-a 70-year British study. Spinal Cord. 2017;55(10):891-7.

15. Thietje R, Pouw M, Schulz A. Mortality in patients with traumatic spinal cord injury: descriptive analysis of 62 deceased subjects. J Spinal Cord Med. 2011;34(5):482-7.

16. Berlowitz D. Respiratory problems and management in people with spinal cord injury. Breathe. 2016;12(4):328.

17. Abbasi F, Korooni S. Infectious complications after spinal cord injury. IntechOpen Essentials Spinal Cord Inj Med; 2017.

18. Brodke D. Comparison of anterior and posterior approaches in cervical spinal cord injuries. J Spinal Disord Tech. 2003;16(3):229-35.

19. Dietz V, Colombo G. Recovery from spinal cord injury-underlying mechanisms and efficacy of rehabilitation. Acta Neurochir Suppl. 2004;89:95-100.

\section{Publisher's Note}

Springer Nature remains neutral with regard to jurisdictional claims in published maps and institutional affiliations. 